\title{
Increased isobutanol production in Saccharomyces cerevisiae by overexpression of genes in valine metabolism
}

\author{
Xiao Chen", Kristian F Nielsen, Irina Borodina, Morten C Kielland-Brandt and Kaisa Karhumaa
}

\begin{abstract}
Background: Isobutanol can be a better biofuel than ethanol due to its higher energy density and lower hygroscopicity. Furthermore, the branched-chain structure of isobutanol gives a higher octane number than the isomeric $n$-butanol. Saccharomyces cerevisiae was chosen as the production host because of its relative tolerance to alcohols, robustness in industrial fermentations, and the possibility for future combination of isobutanol production with fermentation of lignocellulosic materials.

Results: The yield of isobutanol was improved from 0.16 to $0.97 \mathrm{mg}$ per g glucose by simultaneous overexpression of biosynthetic genes ILV2, ILV3, and ILV5 in valine metabolism in anaerobic fermentation of glucose in mineral medium in S. cerevisiae. Isobutanol yield was further improved by twofold by the additional overexpression of BAT2, encoding the cytoplasmic branched-chain amino-acid aminotransferase. Overexpression of ILV6, encoding the regulatory subunit of IIV2, in the ILV2 ILV3 ILV5 overexpression strain decreased isobutanol production yield by threefold. In aerobic cultivations in shake flasks in mineral medium, the isobutanol yield of the ILV2 ILV3 ILV5 overexpression strain and the reference strain were 3.86 and $0.28 \mathrm{mg}$ per g glucose, respectively. They increased to 4.12 and $2.4 \mathrm{mg}$ per g glucose in yeast extract/peptone/dextrose (YPD) complex medium under aerobic conditions, respectively.

Conclusions: Overexpression of genes ILV2, ILV3, ILV5, and BAT2 in valine metabolism led to an increase in isobutanol production in S. cerevisiae. Additional overexpression of ILV6 in the ILV2 ILV3 ILV5 overexpression strain had a negative effect, presumably by increasing the sensitivity of Ilv2 to valine inhibition, thus weakening the positive impact of overexpression of $I L V 2, I L V 3$, and $I L V 5$ on isobutanol production. Aerobic cultivations of the ILV2 ILV3 ILV5 overexpression strain and the reference strain showed that supplying amino acids in cultivation media gave a substantial improvement in isobutanol production for the reference strain, but not for the ILV2 ILV3 ILV5 overexpression strain. This result implies that other constraints besides the enzyme activities for the supply of 2ketoisovalerate may become bottlenecks for isobutanol production after ILV2, ILV3, and ILV5 have been overexpressed, which most probably includes the valine inhibition to Ilv2.
\end{abstract}

\section{Background}

Environmentally friendly production of biofuels is a target of great interest due to climate change and the need for renewable transportation fuels. Microbial production of chemicals to be used as liquid biofuels will allow the use of renewable raw materials such as lignocellulose.

\footnotetext{
* Correspondence: xc@bio.dtu.dk

Center for Microbial Biotechnology, Department of Systems Biology, Technical University of Denmark, Søltofts Plads, Building 223, DK-2800 Kgs, Lyngby, Denmark
}

(c) 2011 Chen et al; licensee BioMed Central Ltd. This is an Open Access article distributed under the terms of the Creative Commons Attribution License (http://creativecommons.org/licenses/by/2.0), which permits unrestricted use, distribution, and reproduction in any medium, provided the original work is properly cited.
Optimally, biomass from agricultural and forestry waste products could be used as raw material.

Bioethanol is the most well established biofuel, with existing commercial production. Several pilot plants are in operation for lignocellulosic ethanol production in several countries. However, the chemical properties of ethanol, such as a high tendency to absorb water, are not optimal for all purposes. For many purposes, such as a jet fuel, improved properties are required with regard to hygroscopicity and energy density. Higher alcohols, such as $n$-butanol and isobutanol, represent
Ciomed Central 
possible alternatives. Compared with $n$-butanol, isobutanol has the advantage of having a higher octane number, and the possibility of usage outside the fuel industry as well [1].

Microbial production of isobutanol has been studied in food fermentations and alcoholic beverages for flavour profiling since the 1970s [2,3]. In recent years, production of isobutanol has been investigated as a biofuel in engineered Escherichia coli to reach a concentration of $22 \mathrm{~g} / \mathrm{l}$ during aerobic cultivations [4]. However, as isobutanol concentrations over $15 \mathrm{~g} / \mathrm{l}$ are toxic to $E$. coli [5], this concentration may also be close to the maximal possible production in this bacterium. Since Corynebacterium glutamicum is more tolerant to isobutanol than is $E$. coli, it was engineered as a host and produced about $4 \mathrm{~g} / \mathrm{l}$ of isobutanol in the presence of oxygen [5]. Yeast is well known to be tolerant to alcohols. Saccharomyces cerevisiae is tolerant to up to $20 \%$ ethanol [6]. In a test of many microbial strains for butanol tolerance, baker's yeast $S$. cerevisiae and Lactobacilli were the only microbes able to grow in butanol concentrations higher than $20 \mathrm{~g} / 1$ [7]. In addition, yeast is relatively robust in other respects, commonly used in fermentations with harsh conditions, and its outstanding performance in lignocellulosic hydrolysates would enable future combination of the higher alcohol production with fermentation of lignocellulosic materials. Yeast naturally produces small amounts of higher alcohols through the degradation of amino acids $[8,9]$, such as isobutanol among others $[2,3]$. These are of great importance in the flavour profiles of beer and wine, as they generate desired fruity aromas in these products when produced in favourable amounts. Use of a host that naturally produces isobutanol may in principle offer an opportunity to avoid the use of heterologous pathways, which often require extensive work for optimal expression. Because of all these advantages, S. cerevisiae is a potential alternative host for higher alcohol production.

We studied the effect of concomitant overexpression of several structural genes for the endogenous yeast valine biosynthetic pathway (Figure 1) for anaerobic isobutanol production in S. cerevisiae. It is well studied how yeast can convert valine to isobutanol [9], thereby isobutanol is a side product of valine synthesis, and our interest was whether increased flux in the valine biosynthetic pathway would increase isobutanol production. Isobutanol can be produced from pyruvate via formation of 2-ketoisovalerate (Figure 1). First, acetolactate synthase (Ilv2 + Ilv6) converts two molecules of pyruvate to 2 -acetolactate, which is then reduced to 2,3 dihydroxyisovalerate by acetohydroxyacid reductoisomerase (Ilv5). Further, 2,3-dihydroxyisovalerate is converted

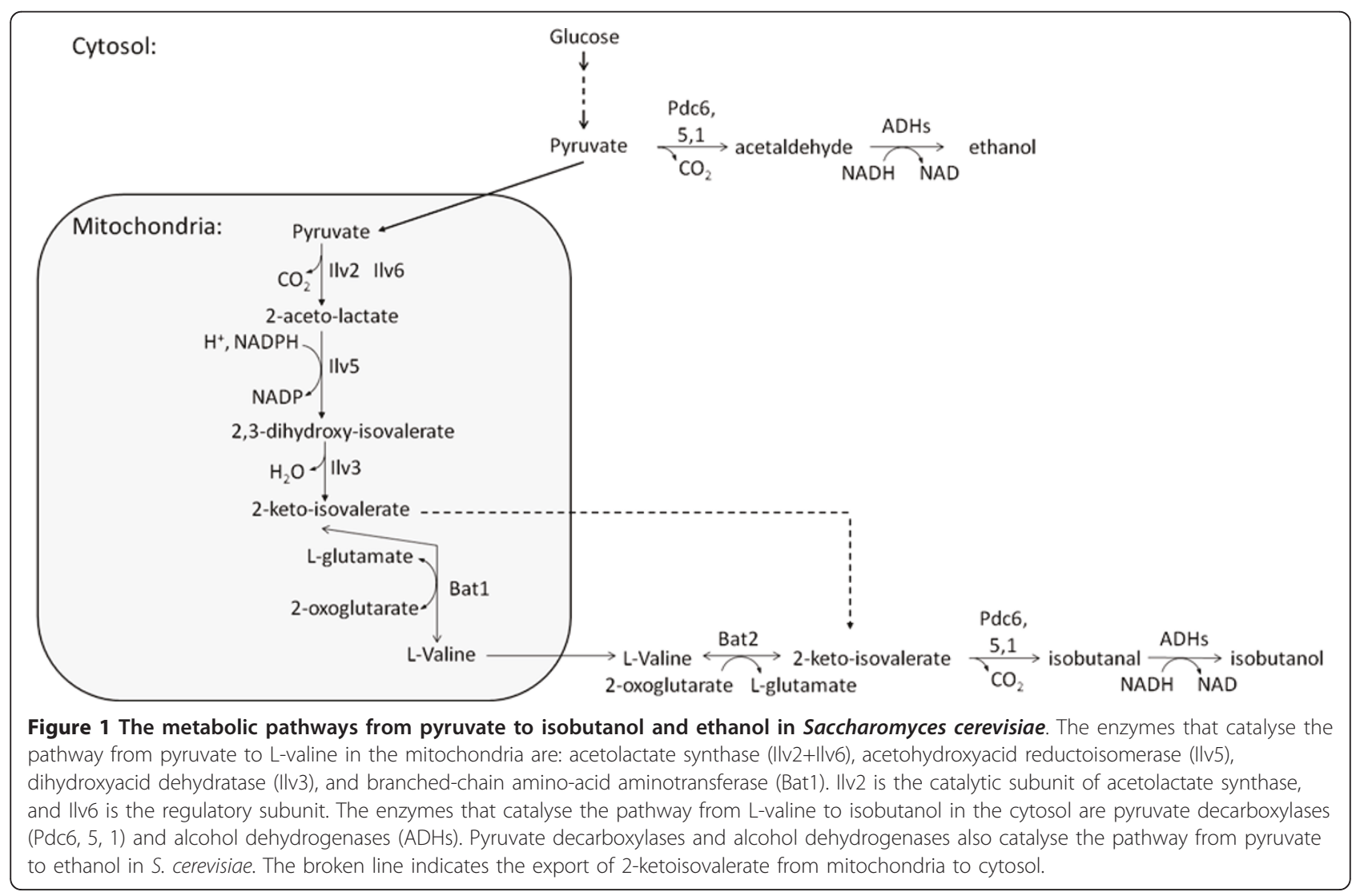


to 2-ketoisovalerate by dihydroxyacid dehydratase (Ilv3). Ilv6 is the regulatory subunit of acetolactate synthase and an enhancer of Ilv2 catalytic activity. The bidirectional reaction between 2-ketoisovalerate and valine is catalysed by the branched-chain amino-acid aminotransferases (Bat1 and Bat2, present in the mitochondrial matrix and the cytosol, respectively). Finally, the 2-ketoisovalerate is converted to isobutanol by pyruvate decarboxylases (PDC) and alcohol dehydrogenases (ADH). We have here used overexpression of the valine pathway genes $I L V 2, I L V 3$ and $I L V 5$ to generate a sixfold higher isobutanol yield. The finding that the isobutanol production in yeast that ferments a rich, complex medium could be increased by overexpression of Bat2 [10] prompted us to overexpress $B A T 2$ additional to the overexpression of $I L V 2, I L V 3$ and $I L V 5$ in synthetic medium. This turned out to increase isobutanol production further by twofold. However, overexpression of $I L V 6$, encoding the regulatory subunit of the first committed step in valine biosynthesis, weakened the impact of overexpression of $I L V 2, I L V 3$, and $I L V 5$ on isobutanol production. After the initiation of the present work, the results of somewhat similar genetic approaches on isobutanol production in $S$. cerevisiae appeared in patent applications $[11,12]$, but not in the scientific literature.

\section{Results and discussion}

The objective of this work was to study isobutanol formation in S. cerevisiae, and to improve isobutanol production by metabolic engineering. We studied overexpression of the genes ILV2, ILV3, ILV5, ILV6, and $B A T 2$, involved in valine metabolism, in different combinations, and investigated the isobutanol production in the constructed strains.

\section{Improvement of anaerobic isobutanol production by overexpression of genes in valine metabolism}

To overexpress the genes, $I L V 2, I L V 3$, and $I L V 5$, which encode the catalysts for the conversion of pyruvate to 2ketoisovalerate (direct precursor of L-valine), the coding regions were fused with the $S$. cerevisiae PGK1 promoter. The resulting PGK1-ILV2, PGK1-ILV3 and PGK1ILV5 DNA fusion fragments were cloned into integration vectors YDp-L, YDp-W and YDp-H [13], respectively. The three resulting plasmids were linearised by cleavage of the $I L V$ genes and successively integrated into the genome of CEN.PK 2-1C (MATa leu2-3, 112 his3- 11 ura3-52 trp1-289 MAL2-8(Con) MAL3 SUC3) (a kind gift of P Kötter, Goethe Universität Frankfurt, Frankfurt, Germany The resulting strain was designated ILV235_XCY561 (ILV2 ILV3 ILV5 overexpression strain). Successful genomic integration was confirmed by analytical polymerase chain reaction (PCR) on chromosomal DNA. The copy number of the integrated gene was estimated by performing quantitative real-time PCR with genomic DNA as template $[14,15]$. The estimates of the copy numbers of $I L V 2, I L V 3$ and ILV5 in ILV235_XCY561 given by the quantitative PCR were 4.1 $\pm 0.90,2.1 \pm 0.65$ and $3.6 \pm 1.12$ times larger than those in the reference strain, respectively. Multiple integrations may have happened in some cases. The expression of $I L V 2, I L V 3$ and $I L V 5$ at the transcriptional level in ILV235_XCY561 was also measured by quantitative real-time PCR. The mRNA levels of $I L V 2, I L V 3$ and ILV5 in ILV235_XCY561 measured by quantitative (qPCR) were $6.42 \pm 2.20,9.98 \pm 1.31$ and $3.24 \pm 0.61$ times larger than those in the reference strain, respectively. Overexpression of these three genes at mRNA level was proved. However, no enzymatic assays were performed to confirm the overexpression since the reagents needed are not commercially available.

The ILV2 ILV3 ILV5 overexpressing strain (ILV235_XCY561) and the reference strain (CEN.PK 113-5D) were cultivated in mineral glucose medium supplemented with uracil in fermenters under anaerobic conditions. Primary metabolite concentrations were measured by high-performance liquid chromatography (HPLC) throughout the fermentation. Isobutanol concentration was measured by gas chromatography (GC) only from the samples taken at the end of fermentations after glucose depletion, due to the large sample volume needed for reliable measurements. The ILV2 ILV3 ILV5 overexpression strain produced $0.97 \pm 0.14 \mathrm{mg}$ isobutanol per g glucose, which was sixfold higher than the reference strain (Figure 2). No difference was detected between the ILV2 ILV3 ILV5 overexpression strain and the reference strain in the production of biomass, ethanol, pyruvate, succinate, glycerol, acetate and $\mathrm{CO}_{2}$ (Table 1). Our interpretation is that overexpression of gene $I L V 2, I L V 3$, and $I L V 5$ led to a higher concentration of 2-ketoisovalerate, which resulted in higher isobutanol production.

The ILV2 ILV3 ILV5 overexpression strain had a maximum specific growth rate of $0.29 \pm 0.02$ per $h$, which was slower than the maximum specific growth rate of the reference strain, which was $0.38 \pm 0.02$ per $h$. The slower growth rate may be due to a metabolic imbalance caused by the overexpression of the $I L V$ genes, which affects some amino acids pools, or due to insufficient expression of the selection markers, which were put at different loci and might not work with the same efficiency as at their wild type locations.

$B A T 2$ encodes a branched-chain amino-acid aminotransferase, which catalyses the first reaction in the catabolism of valine in the cytosol [16]. BAT2 is highly expressed during stationary phase and repressed during logarithmic growth, which is the opposite way of the regulation of the mitochondrial branched-chain amino- 


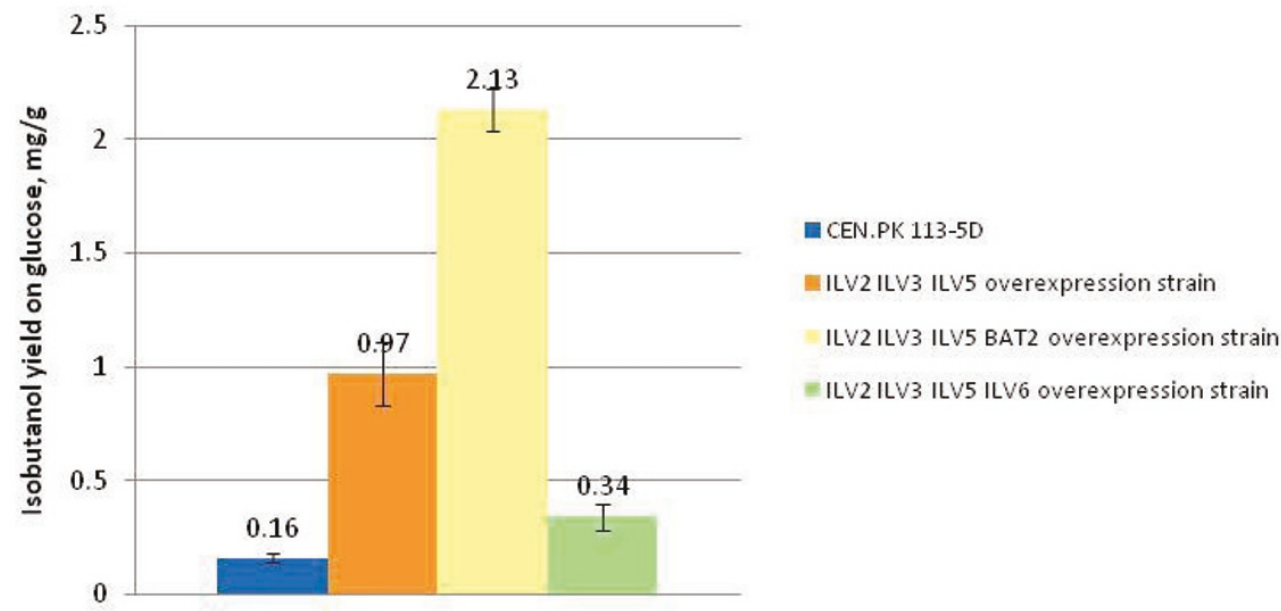

Figure 2 Effects of overexpression of $I L V$ genes on isobutanol yield under anaerobic conditions. Isobutanol yields (mg per $\mathrm{g}$ glucose) of the reference strain (CEN.PK 113-5D) and the ILV2 ILV3 ILV5, the ILV2 ILV3 ILV5 BAT2, and the ILV2 ILV3 ILV5 ILV6 overexpression strains were presented with columns with different colours, and the values are shown on the tops of each column. All cultivations were carried out in fermenters in mineral medium with $40 \mathrm{~g}$ glucose/l under anaerobic conditions.

acid aminotransferase, encoded by $B A T 1$ [17]. It has been previously shown that overexpression of $B A T 2$ alone increases isobutanol concentration in wine fermentations [18]. We therefore decided to investigate whether BAT2 overexpression could complement the valine pathway overexpression and result in higher yields and concentrations of isobutanol.

An ILV2 ILV3 ILV5 BAT2 overexpression strain, ILV235BAT2_XCY715, was thus constructed by using the same promoter and the same molecular strategy. The estimate of the copy number of gene $B A T 2$ in ILV235BAT2_XCY715 was $1.5 \pm 0.50$ times larger than the one in the reference strain, which was in accordance with the expected copy number of two. The overexpression of BAT2 at the transcriptional level in ILV235BAT2_XCY715 was $90.82 \pm 0.45$ times larger than that in the reference strain. The different overexpression level among $I L V 2, I L V 3, I L V 5$ and $B A T 2$, reflects the fact that expression level controlled by inserted promoters depends on the surrounding sequence. Anaerobic fermentations with ILV235BAT2_XCY715 were carried out in fermenters under the conditions described above. The GC results showed that the ILV2 ILV3 ILV5 BAT2 overexpression strain produced 13 times more isobutanol per g glucose than the reference strain. This is an improvement of twofold over that of the ILV2 ILV3

Table 1 Effects of gene overexpression on growth rates and product yields under anaerobic batch fermentations ${ }^{a}$

\begin{tabular}{|c|c|c|c|c|}
\hline Strain & $\begin{array}{l}\text { Reference } \\
\text { strain }^{\text {b }}\end{array}$ & $\begin{array}{l}\text { ILV2 ILV3 ILV5 } \\
\text { overexpression strain }^{\text {b }}\end{array}$ & $\begin{array}{l}\text { ILV2 ILV3 ILV5 BAT2 } \\
\text { overexpression strain }^{\text {b }}\end{array}$ & $\begin{array}{l}\text { ILV2 ILV3 ILV5 ILV6 } \\
\text { overexpression strain }^{\text {b }}\end{array}$ \\
\hline Specific growth rate, per $\mathrm{h}$ & $0.38 \pm 0.02$ & $0.29 \pm 0.02$ & $0.16 \pm 0.01$ & $0.18 \pm 0.00$ \\
\hline $\begin{array}{l}\text { Biomass }\left(\mathrm{CH}_{1.78} \mathrm{O}_{0.6} \mathrm{~N}_{0.19}\right) \text { yield, } \\
\text { g/g glucose }\end{array}$ & $0.10 \pm 0.00$ & $0.11 \pm 0.01$ & $0.07 \pm 0.01$ & $0.11 \pm 0.00$ \\
\hline Ethanol yield, g/g glucose & $0.38 \pm 0.01$ & $0.37 \pm 0.02$ & $0.34 \pm 0.01$ & $0.37 \pm 0.00$ \\
\hline Pyruvate yield, g/g glucose & $\begin{array}{l}0.0011 \pm \\
0.007\end{array}$ & $0.0016 \pm 0.0007$ & $0.0032 \pm 0.0006$ & $0.0028 \pm 0.0001$ \\
\hline Succinate yield, g/g glucose & $\begin{array}{l}0.0016 \pm \\
0.0006\end{array}$ & $0.0006 \pm 0.0001$ & $0.0028 \pm 0.0001$ & $0.0035 \pm 0.0003$ \\
\hline Glycerol yield, g/g glucose & $0.100 \pm 0.008$ & $0.087 \pm 0.006$ & $0.095 \pm 0.001$ & $0.099 \pm 0.003$ \\
\hline Acetate yield, g/g glucose & $\begin{array}{l}0.0076 \pm \\
0.0014\end{array}$ & $0.0088 \pm 0.0010$ & $0.0110 \pm 0.0006$ & $0.0069 \pm 0.0003$ \\
\hline $\mathrm{CO}_{2}$ yield, $\mathrm{g} / \mathrm{g}$ glucose & $0.32 \pm 0.01$ & $0.39 \pm 0.01$ & $0.37 \pm 0.04$ & $0.41 \pm 0.03$ \\
\hline Carbon balance deviation, $\%^{\mathrm{b}}$ & $5.9 \pm 2.2$ & $3.0 \pm 4.0$ & $10.9 \pm 1.7$ & $1.3 \pm 1.7$ \\
\hline
\end{tabular}

${ }^{\mathrm{a}}$ The mineral medium with $40 \mathrm{~g} / \mathrm{l}$ of glucose was used.

${ }^{\mathrm{b}}$ The reference strain used was CEN.PK 113-5D; The ILV2 ILV3 ILV5 overexpression strain used was ILV235_XCY561; The ILV2 ILV3 ILV5 BAT2 overexpression strain used were ILV235BAT2_XCY715 and ILV235BAT2_XCY723; The ILV2 ILV3 ILV5 ILV6 overexpression strain used was ILV2356_XCY605. 
ILV5 overexpression strain (Figure 2). The biomass yield on glucose of the ILV2 ILV3 ILV5 BAT2 overexpression strain was $0.07 \pm 0.01 \mathrm{~g}$ per g glucose, which was lower than the biomass yields of the ILV2 ILV3 ILV5 overexpression strain and the reference strain, which were 0.10 \pm 0.00 and $0.11 \pm 0.01$, respectively. A carbon balance calculation showed that after accounting for carbon in produced biomass, isobutanol, ethanol, pyruvate, succinate, glycerol, acetate and $\mathrm{CO}_{2}$, there was about $11 \%$ of carbon missing (Table 1). We have investigated whether the missing carbon could be explained by the increase in the production of 3-methylbutanol and 2-methylbutanol, since the BAT2 encoding aminotransferase also catalyses the first step in the leucine and isoleucine catabolism pathways, which produce 3-methylbutanol and 2-methylbutanol, respectively $[9,19,20]$. GC analysis showed that the yield of 3-methylbutanol increased from 0.28 to $0.48 \mathrm{mg}$ per g glucose $(0.0330 \%$ carbon) compared to the reference strain, and there was no increase observed in 2-methylbutanol yield. These increases, however, were not large enough to explain the missing carbon. The deviation in carbon balance could be due to some other products not included in the present analysis. The time profiles of anaerobic fermentations of the ILV2 ILV3 ILV5 BAT2 overexpression strain and the CEN.PK 113-5D reference strain are presented in Figure 3a, b, respectively. Glucose consumption and all measured production rates were much higher in the reference strain than in the ILV2 ILV3 ILV5 BAT2 overexpression strain. The maximum specific growth rate of the ILV2 ILV3 ILV5 BAT2 overexpression strain was $0.16 \pm 0.01$ per $h$, and thus much lower than that of the reference strain and the ILV2 ILV3 ILV5 overexpression strain, which has the growth rate at $0.38 \pm 0.02$ and $0.29 \pm 0.02$ per $h$, respectively. The decrease in growth rate could be due to the same reasons as explained earlier for the slow growth rate of the ILV2 ILV3 ILV5 overexpression strain. The very high overexpression of $B A T 2$ might result in a further metabolic imbalance of some amino acids pools, and could be the cause the further drop of the growth rate of the ILV2 ILV3 ILVS $B A T 2$ overexpression strain. An independent transformant of the ILV2 ILV3 ILVS overexpression strain with the BAT2 overexpression construct, named ILV235BAT2_XCY723, was investigated, and it behaved identically to ILV235BAT2_XCY715.

Ilv6 is the regulatory subunit of acetolactate synthase and has been described as an enhancer of Ilv2 catalytic activity. To investigate whether ILV6 overexpression would further improve isobutanol production by possibly approaching equimolar amounts of both proteins, ILV6 was overexpressed in the strain background with $I L V 2, I L V 3$ and $I L V 5$ overexpression. The resulting strain was designated ILV2356_XCY605, here also referred to as the ILV2 ILV3 ILV5 ILV6 overexpression strain. The estimate of the copy number of $I L V 6$ in ILV2356_XCY605 was $2.8 \pm 1.67$ times larger than that in the reference strain. We also estimated the copy number of ILV6 in ILV235BAT2_XCY715 and that of BAT2 in ILV2356_XCY605. Their copy numbers were $0.9 \pm 0.31$ and $1.0 \pm 0.42$ times, respectively, compared to the reference strain, which was in agreement with the fact that these two genes were not overexpressed in their respective strains. The overexpression of $I L V 6$ at the transcriptional level in ILV2356_XCY605 was $8.07 \pm$ 1.14 times larger than that in the reference strain. Unexpectedly, integration of the overexpression construct with ILV6 caused threefold less isobutanol production, namely $0.34 \mathrm{mg}$ per g glucose (Figure 2), and a drop of the maximum specific growth rate to $0.18 \pm 0.00$ per $h$. The yields of the other measured products, that is, biomass, ethanol, pyruvate, succinate, glycerol, acetate and $\mathrm{CO}_{2}$ were largely unaffected (Table 1 ). We interpret the lower yield of isobutanol upon overexpression of ILV6 to be due to an increased sensitivity of Ilv2 to valine inhibition, weakening the positive impact of overexpression of ILV2, ILV3, and ILV5 on increasing isobutanol production in S. cerevisiae, since Ilv6 stimulates Ilv2 catalytic activity sevenfold to tenfold and confers Ilv2 sensitivity to valine inhibition $[21,22]$.

\section{Influence of various media on isobutanol production and growth rate}

The ILV2 ILV3 ILV5 overexpression strain and the CEN. PK 113-5D reference strain were cultivated under aerobic conditions in shake flasks to further investigate the effect of valine pathway overexpression on growth rates and isobutanol production. Buffered mineral medium with $40 \mathrm{~g}$ glucose/l and yeast extract/peptone/dextrose (YPD) complex medium with $17 \mathrm{~g}$ glucose/l were used. The growth rates and the main product yields are shown in Table 2. In the mineral medium, the $I L V 2$ ILV3 ILV5 overexpression strain had a threefold lower maximum specific growth rate $(0.110$ per $h)$ than the reference strain $(0.359$ per $h)$. In YPD, however, they grew at similar growth rates, about 0.5 per h. Our interpretation is that genetic manipulations in the ILV2 ILV3 ILV5 overexpression strain might cause a metabolic imbalance, which perhaps affected some amino acid pools, or the improper functioning of the selection markers. Any of these problems could be compensated for by growing the overexpression strain in the complex medium.

Isobutanol yields of the ILV2 ILV3 ILVS overexpression strain and the reference strain under aerobic cultivation conditions in different media are compared in Figure 4. In mineral medium the ILV2 ILV3 ILV5 overexpression strain produced $3.86 \mathrm{mg}$ isobutanol per $\mathrm{g}$ 

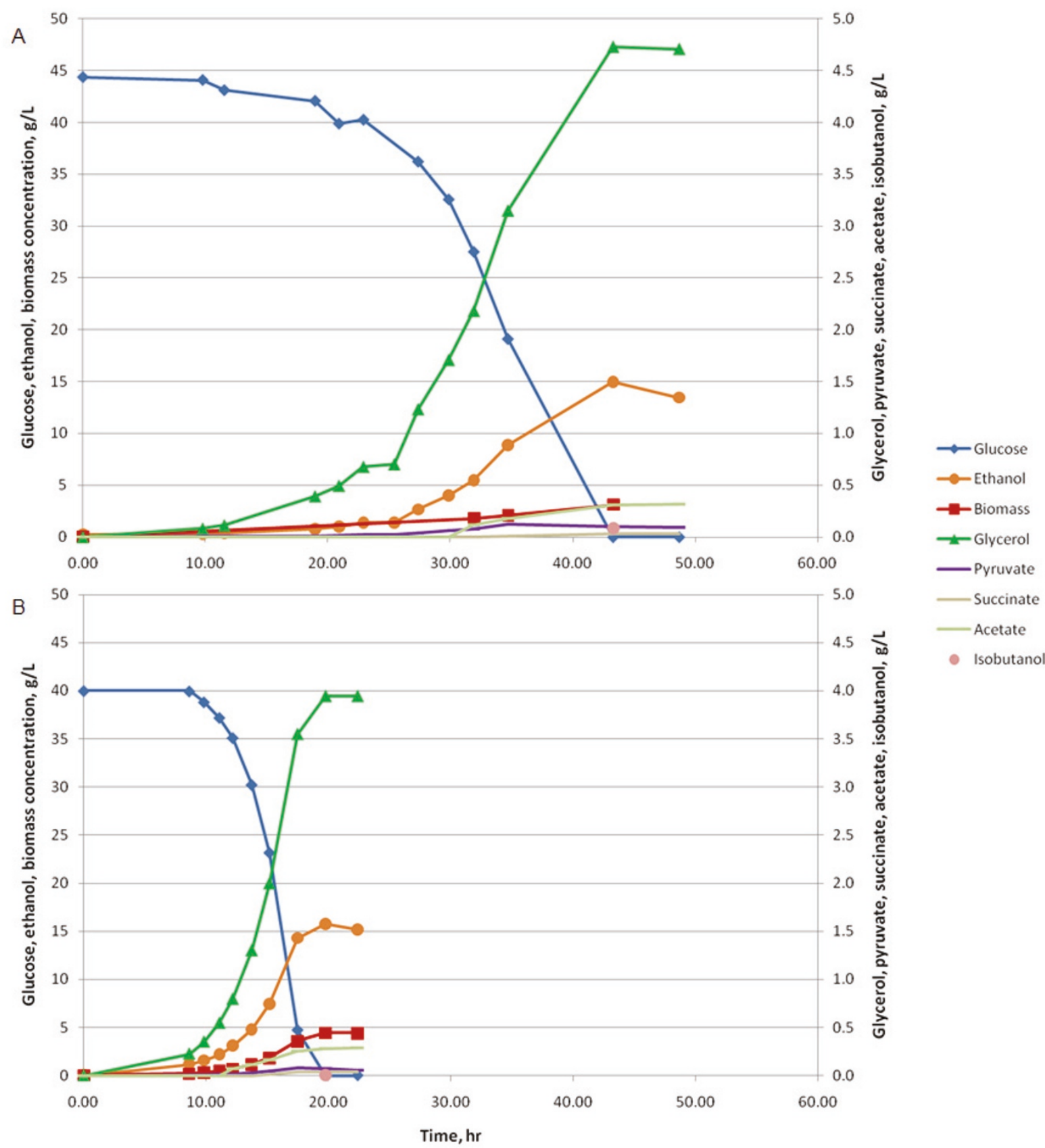

Figure 3 Time profiles of fermentations of ILV2 ILV3 ILV5 BAT2 overexpression (a) and reference strain (b). The ILV2 ILV3 ILV5 BAT2 overexpression strain and the reference strain CEN.PK 113-5D were cultivated under anaerobic batch fermentations in mineral medium with 40 g glucose/l. The concentrations of glucose, biomass, and products are plotted as a function of time. Isobutanol concentrations were measured after glucose depletion in both cases. Fermentations were performed in triplicate, representative cultivations are shown.

glucose, and the reference strain produced $0.28 \mathrm{mg}$ isobutanol per g glucose. In YPD complex medium the ILV2 ILV3 ILV5 overexpression strain and the reference strain produced 4.12 and $2.4 \mathrm{mg}$ isobutanol per g glucose, respectively. There were $2.12 \mathrm{mg}$ isobutanol per $\mathrm{g}$ glucose of increase for the reference strain, and only
$0.26 \mathrm{mg}$ isobutanol per g glucose of increase for the ILV2 ILV3 ILV5 overexpression strain. We interpret this due to both overexpression of ILV2, ILV3, and ILV5 and uptake of valine from the complex medium caused a strong increase of the pool of valine, and thereby an increase of isobutanol production. Since the provision of 
Table 2 Aerobic batch cultivations of the ILV2 ILV3 ILV 5 overexpression strain and reference strain in shake flasks ${ }^{a}$

\begin{tabular}{lllll}
\hline & \multicolumn{2}{l}{ Buffered mineral medium } & \multicolumn{2}{l}{ YPD complex medium } \\
\cline { 2 - 5 } & $\begin{array}{l}\text { Reference } \\
\text { stain }^{\mathbf{b}}\end{array}$ & $\begin{array}{l}\text { ILV2 ILV3 ILV5 overexpression } \\
\text { strain }^{\mathbf{b}}\end{array}$ & $\begin{array}{l}\text { Reference } \\
\text { strain }\end{array}$ & $\begin{array}{l}\text { ILV2 ILV3 ILV5 overexpression } \\
\text { strain }\end{array}$ \\
\hline Specific growth rate, per $\mathrm{h}$ & $0.36 \pm 0.00$ & $0.11 \pm 0.00$ & $0.52 \pm 0.00$ & $0.50 \pm 0.00$ \\
\hline $\begin{array}{l}\text { Biomass }\left(\mathrm{CH}_{1.78} \mathrm{O}_{0.6} \mathrm{~N}_{0.19}\right) \text { yield, g/g } \\
\text { glucose }\end{array}$ & $0.33 \pm 0.06$ & $0.14 \pm 0.05$ & $0.34 \pm 0.00$ & $0.35 \pm 0.00$ \\
\hline Ethanol yield, g/g glucose & $0.22 \pm 0.05$ & $0.28 \pm 0.10$ & $0.12 \pm 0.01$ & $0.19 \pm 0.02$ \\
\hline Pyruvate yield, g/g glucose & $0.0002 \pm 0.0000$ & $0.0002 \pm 0.0000$ & $0.0137 \pm 0.0003$ & $0.0134 \pm 0.0005$ \\
\hline Succinate yield, g/g glucose & $0.20 \pm 0.02$ & $0.26 \pm 0.01$ & $0.02 \pm 0.00$ & $0.01 \pm 0.00$ \\
\hline Glycerol yield, g/g glucose & $0.006 \pm 0.006$ & $0.026 \pm 0.017$ & $0.002 \pm 0.000$ & $0.013 \pm 0.000$ \\
\hline Acetate yield, g/g glucose & $0.0000 \pm 0.0000$ & $0.0052 \pm 0.0022$ & $0.0929 \pm 0.0047$ & $0.0929 \pm 0.0018$ \\
\hline
\end{tabular}

${ }^{a}$ The cultivations were carried out in shake flask. Buffered mineral medium containing $40 \mathrm{~g} / \mathrm{l}$ glucose and YPD complex medium containing $17 \mathrm{~g} / \mathrm{l}$ glucose were used.

${ }^{\mathrm{b}}$ The reference strain used was CEN.PK 113-5D. The overexpression strain used was ILV235_XCY561.

YPD = yeast extract/peptone/dextrose.

valine in the medium by using the YPD complex medium did not increase the isobutanol production yield of the ILV2 ILV3 ILVS overexpression strain much, it appears that other constraints besides the enzyme activities for the supply of 2-ketoisovalerate in the ILV2 ILV3 ILV5 overexpression strain might have become bottlenecks. These could include valine inhibition to Ilv2, transportation of 2-ketoisovalerate or valine from mitochondria to cytosol, and affinities of PDCs to 2-ketoisovalerate in cytosol.

In this study, the isobutanol production yield was increased first by simultaneously overexpression genes, $I L V 2, I L V 3$ and $I L V 5$ in valine biosynthetic pathway. However, which gene(s) out of these three is (are) needed to reach the same increased level of isobutanol yield, was not investigated in this study. Even though the isobutanol production yield was improved by ninefold by overexpression of $I L V 2, I L V 3, I L V 5$, and $B A T 2$, in valine biosynthetic and degradation pathways, the isobutanol production yield was still too low for commercial applications. The low production of isobutanol was probably due to the regulation control of valine production in mitochondria, which limited the flux toisobutanol. Moving the pathway from pyruvate to 2ketoisovalerate from mitochondria to cytosol would benefit the production of isobutanol in yeast.

\section{Conclusions}

Isobutanol production yield on glucose was first increased from 0.16 to $0.97 \mathrm{mg}$ isobutanol per gram of glucose by overexpression of genes $I L V 2, I L V 3$ and ILV5, which encode the catalysts for the conversion of

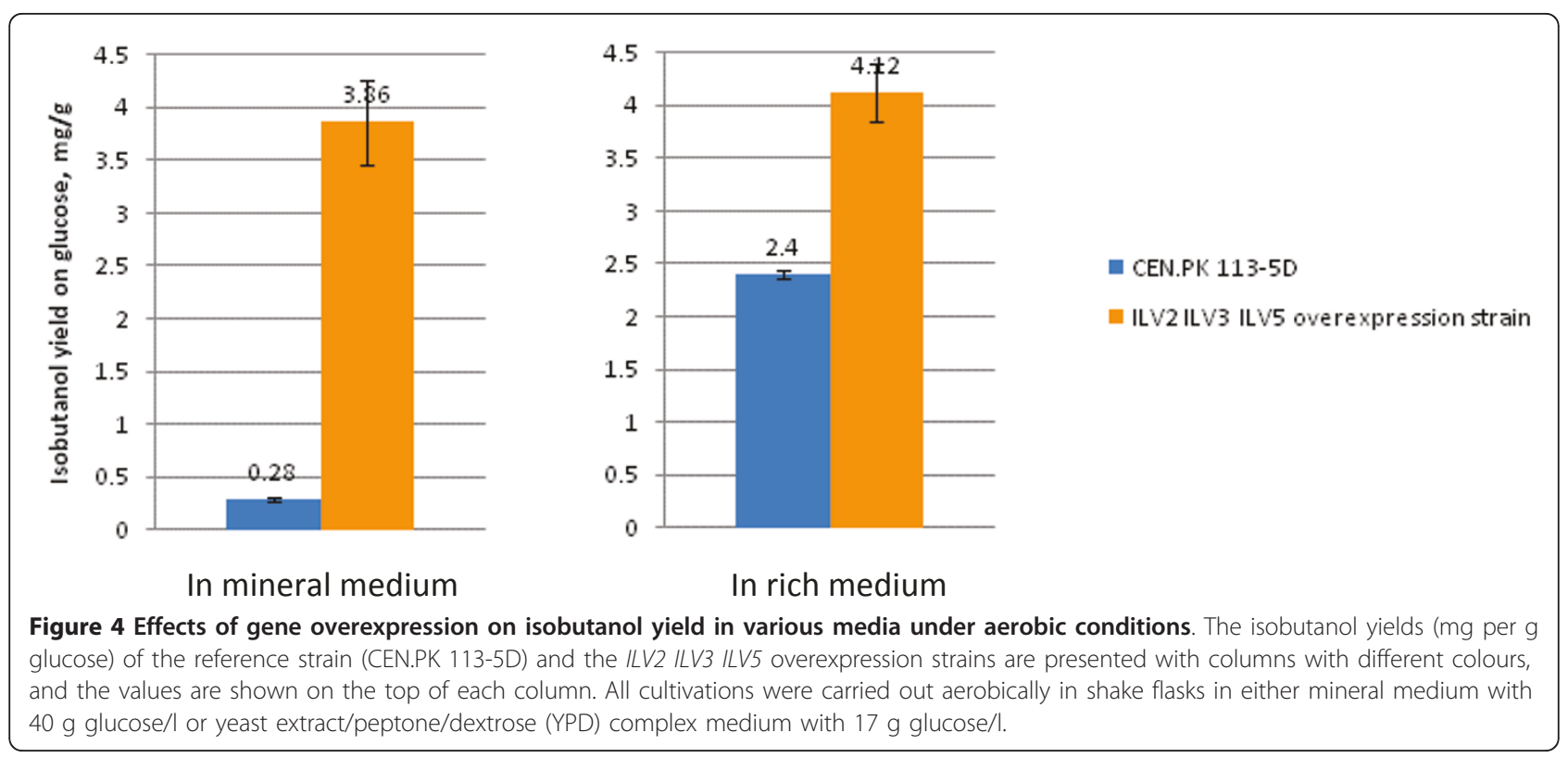


pyruvate to 2-ketoisovalerate, the immediate precursor of valine. With the background of ILV2 ILV3 ILV5 overexpression, isobutanol yield was further improved twofold by overexpression of $B A T 2$, encoding the catalyst for the first step of valine catabolism. Also with the background of the ILV2 ILV3 ILVS overexpression, overexpression of $I L V 6$, encoding a regulatory subunit that combines with Ilv2, which catalyses the first committed step in valine biosynthesis, resulted in a threefold drop of the yield of isobutanol. We interpret this to be due to an increased sensitivity of Ilv2 to valine inhibition, weakening the positive impact of overexpression of $I L V 2$, ILV3, and ILV5 on increasing isobutanol production.

Aerobic cultivation of the ILV2 ILV3 ILV5 overexpression strain and the reference strain in shake flasks indicated that uptake of valine has the same effect on increasing the valine pool and thereby isobutanol production as on increasing the flux capacity from pyruvate to 2 -ketoisovalerate by overexpression of the three genes. Thus, the enzyme activities for the supply of 2ketoisovalerate were not a bottleneck any longer in the ILV2 ILV3 ILV5 overexpression strain. Other bottlenecks, such as the regulation of valine production, export of valine or 2-ketoisovalerate from mitochondria to cytosol, or the affinities of PDCs to 2-ketoisovalerate in cytosol, should be investigated in order to further increase the yield of isobutanol.

\section{Methods}

\section{Media and culture conditions}

The mineral medium, which was used in all anaerobic fermentations, had the following composition (per litre): $\left(\mathrm{NH}_{4}\right)_{2} \mathrm{SO}_{4}, 10 \mathrm{~g} ; \mathrm{KH}_{2} \mathrm{PO}_{4}, 6$ g; $\mathrm{MgSO}_{4} \cdot 7 \mathrm{H}_{2} \mathrm{O}, 1$ g; Antifoam 289 (A-5551; Sigma-Aldrich, St Louis, MO, USA), $0.2 \mathrm{ml}$; trace metal solution, $2 \mathrm{ml}$; vitamin solution, 2 $\mathrm{ml}$; and ergosterol solution, $2 \mathrm{ml}$. This medium was supplemented with $40 \mathrm{~g} / \mathrm{l}$ glucose and $0.1 \mathrm{~g} / \mathrm{l}$ uracil. The trace metal solution consisted of the following (per litre): ethylenediaminetetraacetic acid (EDTA) (sodium salt), 15.0 g; $\mathrm{ZnSO}_{4} \cdot 7 \mathrm{H}_{2} \mathrm{O}, 4.5 \mathrm{~g} ; \mathrm{MnCl}_{2} \cdot 2 \mathrm{H}_{2} \mathrm{O}, 0.84 \mathrm{~g}$; $\mathrm{CoCl}_{2} \cdot 6 \mathrm{H}_{2} \mathrm{O}, 0.3 \mathrm{~g} ; \mathrm{CuSO}_{4} \cdot 5 \mathrm{H}_{2} \mathrm{O}, 0.3 \mathrm{~g} ; \mathrm{Na}_{2} \mathrm{MoO}_{4} \cdot 2 \mathrm{H}_{2} \mathrm{O}$, $0.4 \mathrm{~g} ; \mathrm{CaCl}_{2} \cdot 2 \mathrm{H}_{2} \mathrm{O}, 4.5 \mathrm{~g} ; \mathrm{FeSO}_{4} \cdot 7 \mathrm{H}_{2} \mathrm{O}, 3 \mathrm{~g} ; \mathrm{H}_{3} \mathrm{BO}_{3}, 1$ g; and KI, $0.1 \mathrm{~g}$. The vitamin solution contained the following (per litre): biotin, $0.05 \mathrm{~g} ; p$-aminobenzoic acid, $0.2 \mathrm{~g}$; nicotinic acid, $1 \mathrm{~g}$; calcium pantothenate, $1 \mathrm{~g}$; pyridoxine- $\mathrm{HCl}, 1 \mathrm{~g}$; thiamine- $\mathrm{HCl}, 1 \mathrm{~g}$; and myo-inositol, $25 \mathrm{~g}$. The ergosterol solution contained $2 \mathrm{~g}$ ergosterol and $84 \mathrm{~g}$ Tween 80 in $100 \mathrm{ml}$ pure ethanol.

For the precultivations, $50 \mathrm{ml}$ of mineral medium was used in $500 \mathrm{ml}$ shake flasks, with the exception that 0.1 $\mathrm{g} / \mathrm{l}$ uracil was added when necessary, and no ergosterol was used. The precultures were grown at $30^{\circ} \mathrm{C}$ with shaking at $200 \mathrm{rpm}$ and a start $\mathrm{pH}$ of 5.0.
All aerobic cultivations were performed in $500 \mathrm{ml}$ baffled shake flasks with $100 \mathrm{ml}$ of working volume of either buffered mineral medium or YPD complex medium. Buffered mineral medium contained (per litre): $\left(\mathrm{NH}_{4}\right)_{2} \mathrm{SO}_{4}, 15 \mathrm{~g} ; \mathrm{KH}_{2} \mathrm{PO}_{4}, 28.8 \mathrm{~g} ; \mathrm{MgSO}_{4} \cdot 7 \mathrm{H}_{2} \mathrm{O}, 1 \mathrm{~g}$; Antifoam 289, $0.2 \mathrm{ml}$; trace metal solution, $4 \mathrm{ml}$; vitamin solution, $2 \mathrm{ml}$ and $40 \mathrm{~g}$ glucose. The compositions of trace metal and vitamin solutions were as above, and $0.1 \mathrm{~g} / \mathrm{l}$ uracil was used when necessary. The YPD complex medium contained, per litre, $10 \mathrm{~g}$ of yeast extract, $20 \mathrm{~g}$ of peptone, and $17 \mathrm{~g}$ glucose. The aerobic cultivations were carried out at $30^{\circ} \mathrm{C}$ with shaking at $200 \mathrm{rpm}$ and a start $\mathrm{pH}$ of 5.0.

\section{Strains and strain construction}

All $S$. cerevisiae strains used in this study were derivatives of CEN.PK 2-1C strain (MATa leu2-3, 112 his3- $\Delta 1$ ura3-52 trp1-289 MAL2-8(Con) MAL3 SUC3) (Table 3). Strain CEN.PK 113-5D (MATa SUC2 MAL2-8 ${ }^{\mathrm{C}}$ ura352) and CEN.PK 113-7D (MATa MAL2-8 ${ }^{\mathrm{C}}$ SUC2), were used as reference strains in fermentation and real-time PCR experiments, respectively. For routine cultivation, YPD solid or liquid medium was used. Synthetic dropout (SD) solid media appropriately lacking uracil or amino acids were used for selection of yeast plasmid transformants. Yeast extract/peptone/glycerol (YPG) glycerol-based solid medium (containing, per litre, $10 \mathrm{~g}$ of yeast extract, $20 \mathrm{~g}$ of peptone, and $20 \mathrm{~g}$ of glycerol) was used for petite test before long-term storage of strains in $20 \%$ of glycerol at $-80^{\circ} \mathrm{C}$.

Throughout strain construction, standard molecular biology methods were used. Primers used for PCR amplification of DNA fragments (PGK1 promoter, genes ILV2, ILV3, ILV5, ILV6 and BAT2) from S. cerevisiae are listed in Table 4. Each amplified target gene (ILV2, $I L V 3, I L V 5, I L V 6$, or BAT2) was fused to the downstream end of the PGK1 promoter sequence (1,480 bp) in subsequent PCR through designed overlapping ends between the promoter and the target gene. All preparative PCRs were performed with Phusion high-fidelity DNA polymerase (Finnzymes, Thermo Fisher Scientific, Vantaa, Finland).

The generated blunt end fusion PCR products, PGK1 +ILV2, PGK1+ILV3, PGK1+ILV5, PGK1+ILV6 or PGK1 +BAT2, were cloned into the pCR-Blunt II-TOPO vector by using the Zero Blunt TOPO PCR Cloning Kit (Invitrogen, Life Technologies, Paisley, UK). The resulting plasmids were designated pTOPO_P+ILV2, pTOPO_P+ILV3, pTOPO_P+ILV5, pTOPO_P+ILV6, and pTOPO_P+BAT2, respectively. The PGK1 promoter together with the target gene were cut out from these pTOPO clones, and ligated into vector YDp-L, YDp-W, YDp-H, YDp-U, and YDp-U [13], respectively. The resulting plasmids were designated YDp-L_P+ILV2, 
Table 3 Plasmids and strains

\begin{tabular}{|c|c|c|}
\hline Plasmid or strain & Relevant characteristics & $\begin{array}{l}\text { Source or } \\
\text { reference }\end{array}$ \\
\hline \multicolumn{3}{|l|}{ Plasmid } \\
\hline pCR-Blunt II-TOPO & Cloning vector; $\mathrm{Km}^{\mathrm{r}}$ & Invitrogen \\
\hline YDp-L & pUC9 derivative, with LEU2 marker & [13] \\
\hline YDp-W & pUC9 derivative, with TRP1 marker & [13] \\
\hline YDp-H & pUC9 derivative, with HIS3 marker & [13] \\
\hline YDp-U & pUC9 derivative, with URA3 marker & [13] \\
\hline PTOPO_P+ILV2 & pCR-Blunt II-TOPO with PGK1 promoter and ILV2 gene from Saccharomyces cerevisiae & This study \\
\hline pTOPO_P+ILV3 & pCR-Blunt II-TOPO with PGK1 promoter and ILV3 gene from S. cerevisiae & This study \\
\hline pTOPO_P+ILV5 & pCR-Blunt II-TOPO with PGK1 promoter and ILV5 gene from S. cerevisiae & This study \\
\hline pTOPO_P+ILV6 & pCR-Blunt II-TOPO with PGK1 promoter and ILV6 gene from S. cerevisiae & This study \\
\hline pTOPO_P+BAT2 & pCR-Blunt II-TOPO with PGK1 promoter and BAT2 gene from S. cerevisiae & This study \\
\hline YDp-L_P+ILV2 & Plasmid YDp-L with PGK1 promoter and ILV2 & This study \\
\hline YDp-W_P+ILV3 & Plasmid YDp-W with PGK1 promoter and ILV3 & This study \\
\hline YDp-H_P+ILV5 & Plasmid YDp-H with $P G K 1$ promoter and ILV5 & This study \\
\hline YDp-U_P+ILV6 & Plasmid YDp-U with $P G K 1$ promoter and ILV6 & This study \\
\hline YDp-U_P+BAT2 & Plasmid YDp-U with PGK1 promoter and BAT2 & This study \\
\hline \multicolumn{3}{|l|}{ Strains } \\
\hline CEN.PK 2-1C & MATa leu2-3, 112 his3- $\triangle 1$ ura3-52 trp1-289 MAL2-8(Con) MAL3 SUC3 & P Kötter \\
\hline CEN.PK 113-5D & MATa SUC2 MAL2-8c ura3-52 & P Kötter \\
\hline CEN.PK 113-7D & MATa MAL2-8 SUC2 & P Kötter \\
\hline ILV235_XCY561 & $\begin{array}{l}\text { CEN.PK 2-1C with YDp-H_P+ILV5, YDp-L_P+ILV2, and YDp-W_P+ILV3 inserted into the } \\
\text { genome }\end{array}$ & This study \\
\hline $\begin{array}{l}\text { ILV235BAT2_XCY715, } \\
\text { ILV235BAT2_XCY723 }\end{array}$ & $\begin{array}{l}\text { CEN.PK 2-1C with YDp-H_P+ILV5, YDp-L_P+ILV2, YDp-W_P+ILV3, and YDp-U_P+BAT2 } \\
\text { inserted into the genome. }\end{array}$ & This study \\
\hline ILV2356_XCY605 & $\begin{array}{l}\text { CEN.PK 2-1C with YDp-H_P+ILV5, YDp-L_P+ILV2, YDp-W_P+ILV3, and YDp-U_P+ILV6 inserted } \\
\text { into the genome }\end{array}$ & This study \\
\hline
\end{tabular}

YDp-W_P+ILV3, YDp-H_P+ILV5, YDp-U_P+ILV6 and YDp-U_P+BAT2, respectively (Table 3). They were digested with BglII, BglII, EcoRI, NarI and EagI in the middle of gene $I L V 2, I L V 3, I L V 5, I L V 6$ and $B A T 2$, respectively. The linearised plasmids were chromosomally integrated into yeast strain CEN.PK 2-1C (a kind gift of Peter Kötter, Goethe Universität Frankfurt, Frankfurt, Germany) in various combinations. The strain with plasmids YDp-L_P+ILV2, YDp-W_P+ILV3 and YDp$\mathrm{H} \_\mathrm{P}+\mathrm{ILV} 5$ integrated in the genome was designated ILV235_XCY561. The strain with plasmids YDp-L_P +ILV2, YDp-W_P+ILV3, YDp-H_P+ILV5 and YDp-U_P +ILV6 was designated ILV2356_XCY605. Two identical strains, independently isolated in the last step of construction, with plasmids YDp-L_P+ILV2, YDp-W_P +ILV3, YDp-H_P+ILV5 and YDp-U_P+BAT2 were designated ILV235BAT2_XCY715 and ILV235BAT2_XCY723, respectively. The genomic integration of the plasmid was confirmed by PCR amplifying PGK1 +ILV2, PGK1+ILV3, PGK1+ILV5, PGK1+ILV6 or PGK1 + BAT2 fragment from the genomic DNA of the constructed overexpression strains.

\section{Quantitative real-time PCR}

Quantitative real-time PCR was used for quantifying the copy number of the integrated gene and its transcriptional level in the overexpression strain.

\section{Total genomic DNA isolation}

The overexpression strains and the reference strain were cultivated with shaking in $10 \mathrm{ml}$ YPD medium at $30^{\circ} \mathrm{C}$ overnight. The cells were harvested and lysed with 0.5 $\mathrm{mm}$ acid-washed glass beads in $200 \mu \mathrm{l}$ of breaking buffer through 3 min of vortexing. The breaking buffer contained 2\% Triton X-100, 1\% SDS, $100 \mathrm{mM} \mathrm{NaCl}, 100$ $\mathrm{mM}$ Tris- $\mathrm{Cl}$ and $1 \mathrm{mM}$ EDTA with $\mathrm{pH}$ at 8.0. Then, $200 \mu \mathrm{l} 1 \times$ Tris/EDTA (TE) buffer, which contained 10 $\mathrm{mM}$ Tris- $\mathrm{HCl}$ and $1 \mathrm{mM}$ EDTA, was added to the lysed cells. After centrifugation at $12,000 \mathrm{~g}$ for $5 \mathrm{~min}$, the supernatant was transferred into a new Eppendorf tube. The DNA in the supernatant was precipitated with $1 \mathrm{ml}$ of $100 \%$ ethanol, washed with $1 \mathrm{ml}$ of $70 \%$ ethanol twice, and resuspended in $50 \mu$ l sterile Milli-Q water. The quality and quantity of the isolated genomic DNA was measured using NanoDrop ND-1000 (Thermo 
Table 4 Primer sequences

\begin{tabular}{|c|c|c|c|}
\hline Fragment & Primer & Primer sequence ( $5^{\prime}$ to $\left.3^{\prime}\right)$ & Restriction site \\
\hline \multirow[t]{2}{*}{ PGK1 promoter } & Forward & AAAAAACCCGGGTCTAACTGATCTATCCAAAACTG & Xmal \\
\hline & Reverse & TGTITATATTGTTGTAAAAAGTAGA & \\
\hline \multirow[t]{2}{*}{ ILV2 } & Forward & TCTACTIITACAACAAATATAAAACAATGATCAGACAATCTACGCTAA & \\
\hline & Reverse & AAAAAAGGCGCCCAAGCTTGCAATTTTTGACG & $\mathrm{Narl}$ \\
\hline \multirow[t]{2}{*}{ ILV3 } & Forward & TCTACTIITACAACAAATATAAAACAATGGGCTTGTTAACGAAAGT & \\
\hline & Reverse & AAAAAAGGCGCCCTTTGGTAGAGGTGGCTTCG & $\mathrm{Narl}$ \\
\hline \multirow[t]{2}{*}{ ILV5 } & Forward & TCTACTIITACAACAAATATAAAACAATGTTGAGAACTCAAGCCGC & \\
\hline & Reverse & AAAAAAGGCGCCATTCGCGTTTCGGTTCTTGT & $\mathrm{Narl}$ \\
\hline \multirow[t]{2}{*}{ ILV6 } & Forward & TCTACTIITACAACAAATATAAAACAATGCTGAGATCGTTATTGCA & \\
\hline & Reverse & AAAAAAGACGTCAACATCCCAATATCCGTCCA & Aatll \\
\hline \multirow[t]{2}{*}{ BAT2 } & Forward & TCTACTIITACAACAAATATAAAACAATGACCTTGGCACCCCTAGA & \\
\hline & Reverse & AAAAAAGGCGCCGAATTGTCTTGAGTTGCTTCTAAGGTA & $\mathrm{Narl}$ \\
\hline \multirow[t]{2}{*}{$\mathrm{q} / L V 2$} & Forward & TCCAAGGTTGCCAACGACACAG & \\
\hline & Reverse & TGTTGAGCAGCCCACATTTGATG & \\
\hline \multirow[t]{2}{*}{$q / L V 3$} & Forward & TTGCACCTCCACCTCGTTACAC & \\
\hline & Reverse & ACCGTTGGAAGCGTTGGAAACC & \\
\hline \multirow[t]{2}{*}{$q / L V 5$} & Forward & TTACGCCGTCTGGAACGATGTC & \\
\hline & Reverse & GAACCAATGGCAACGGCCAAAG & \\
\hline \multirow[t]{2}{*}{ q/LV6 } & Forward & TACCATGGTGCGTTGCAGTTCC & \\
\hline & Reverse & AGGTCTTGTTGCGTGTCTGTGC & \\
\hline \multirow[t]{2}{*}{ qBAT2 } & Forward & GAAATCGGCTGGAAAGGCGAAC & \\
\hline & Reverse & CTITGGCCAATGGACCGGTTG & \\
\hline \multirow[t]{2}{*}{ qACT1 } & Forward & TGGATTCTGAGGTTGCTGCTITGG & \\
\hline & Reverse & ACCTTGGTGTCTTGGTCTACCG & \\
\hline
\end{tabular}

${ }^{a}$ Restriction sites used for cloning are shown in bold. The reverse and complementary sequences used for fusion PCRs are shown in italics. The primers for q/LV2 q/LV3 q/LV5 q/LV6 qBAT2 and qACT1 amplifications were used for quantitative real-time polymerase chain reactions.

Fisher Scientific, Vantaa, Finland). The isolated gDNA with good purity and appropriate quantity was used as template for quantitative real-time PCR to determine the copy number of the integrated genes in the overexpression strains.

\section{Total RNA isolation}

The overexpression strains and the reference stain were cultivated aerobically in mineral medium in shake flasks. Cells were harvested when the optical density of the culture was between 4 and 6 at $600 \mathrm{~nm}$. Total RNA was isolated using Tri Reagent LS from Sigma-Aldrich (St Louis, MO, USA) as recommended by manufacturer. The quality and quantity of the isolated RNA was measured using NanoDrop ND-1000 (Thermo Fisher Scientific, Vantaa, Finland). Then DNase treatment was performed to the RNA samples by using deoxyribonuclease I from Sigma-Aldrich (St Louis, MO, USA). The cDNA was made using $\mathrm{M}-\mathrm{MuLV}$ RNase $\mathrm{H}^{+}$reverse transcriptase and random hexamer primer set provided by DyNAmoTM SYBR Green 2-Step qRT-PCR Kit from Finnzymes (Thermo Fisher Scientific, Vantaa, Finland).
The negative control of reverse transcription was carried with the RNA, which was not treated by DNaseout. The cDNA and the negative controls were used as the template for quantitative real-time PCR to determine the transcriptional level of the target genes in the overexpression strains and the reference strain.

The primers used for amplifying the small parts of $I L V 2, I L V 3, I L V 5, I L V 6, B A T 2$, and the reference gene $A C T 1$, are listed in Table 3. The resulting PCR fragment sizes were $80,74,72,76,73$ and $125 \mathrm{bp}$, respectively. The program used for quantitative PCR reactions was as follows: initial denaturation at $95^{\circ} \mathrm{C}$ for $15 \mathrm{~min}$; 40 cycles of denaturation at $94^{\circ} \mathrm{C}$ for $10 \mathrm{~s}$, annealing at $66^{\circ}$ $\mathrm{C}$ for $30 \mathrm{~s}$, fluorescence data collection, extension at $72^{\circ}$ $\mathrm{C}$ for $30 \mathrm{~s}$; final extension at $72^{\circ} \mathrm{C}$ for $10 \mathrm{~min}$; melting curve from 65 to $95^{\circ} \mathrm{C}$. The threshold cycles $(\mathrm{C}(\mathrm{t}) \mathrm{s})$ were calculated with the set threshold value by using Mx3005P software (Agilent Technologies, Santa Clara, $\mathrm{CA})$. The $\Delta \Delta \mathrm{C}(\mathrm{t})$ method was applied for the relative quantification of the copy numbers and the transcription of ILV2, ILV3, ILV5, ILV6, and BAT2 in the overexpression strains with respect to the reference strain. 


\section{Fermentation}

All anaerobic batch fermentations were performed in triplicate in 2-1 fermenters (Braun-Biostat B2, stirred tank, Braun Biotech, Melsungen, Germany) with a working volume of $1.5 \mathrm{l}$. The fermenter was inoculated with a preculture from a shake flask to an optical density of 0.05 at $600 \mathrm{~nm}$. During cultivation the temperature was maintained at $30^{\circ} \mathrm{C}$, agitation was set at $200 \mathrm{rpm}$, and sparging was kept at $1 \mathrm{l}$ of pure nitrogen per min. $\mathrm{pH}$ was maintained at 5.0 by automatic addition of $2 \mathrm{~N}$ $\mathrm{NaOH}$. The $\mathrm{CO}_{2}$ and $\mathrm{O}_{2}$ concentrations in the effluent gas from the fermenter were analysed by gas monitor (Innova 1311, Innova Airtech Instruments, Denmark). Samples were taken throughout the cultivation for optical density measurement, biomass dry weight determination, and high-performance liquid chromatography (HPLC) analysis. Samples for GC analysis were taken when glucose was depleted (defined by the zero value of $\mathrm{CO}_{2}$ in the effluent gas).

\section{Analytical methods}

Optical density was measured at $600 \mathrm{~nm}$ with a Shimadzu UV-Mini 1240 spectrophotometer, (Shimadzu Scientific Instruments, Kyoto, Japan). Dry weight of biomass was determined gravimetrically by filtration of a known volume of culture over a predried and weighed $0.45 \mu \mathrm{m}$-pore-size filter. The filter with biomass was rinsed with a twofold volume of $0.9 \% \mathrm{NaCl}$, dried in a microwave oven at $150 \mathrm{~W}$ for $20 \mathrm{~min}$ and weighed again.

The concentrations of glucose, pyruvate, acetate, succinate, glycerol, and ethanol were measured by using isocratic high-performance liquid chromatography with refractive Index detection on an Agilent 1100 system (Agilent Technologies, Waldbronn, Germany) equipped with cooled autosampler $\left(5^{\circ} \mathrm{C}\right)$. Separation was conducted on an Aminex HPX-87H ion-exclusion column, and $5 \mathrm{mM}$ of $\mathrm{H}_{2} \mathrm{SO}_{4}$ as the mobile phase at a flow rate of $0.6 \mathrm{ml} / \mathrm{min}$ at $60^{\circ} \mathrm{C}$ was used. In all, $20 \mu \mathrm{l}$ of sample was injected, and concentrations were determined against freshly prepared external standards.

Isobutanol was determined using static head space-gas chromatography on a PerkinElmer HS 40 head space sampler (PerkinElmer, Waltham, MA, USA) connected to a Perkin Elmer PE Autosystem gas chromatograph (PerkinElmer, Waltham, MA, USA) equipped with a Flame Ionization Detector and $60 \mathrm{~m}, 0.25 \mathrm{~mm}$ ID, 1 $\mu \mathrm{m}, \mathrm{DB}-5$ capillary column. Samples $(1 \mathrm{ml}$ in $20 \mathrm{ml}$ sealed head space vials) were equilibrated for $5 \mathrm{~min}$ at $60^{\circ} \mathrm{C}$ in the auto sampler. The temperature of the needle and the transfer line was $90^{\circ} \mathrm{C}$. Helium carrier gas was used at 20 psi. The temperatures of the injector and the detector were set to $200^{\circ} \mathrm{C}$ and $250^{\circ} \mathrm{C}$, respectively. The oven temperature program was $1 \mathrm{~min}$ at $60^{\circ} \mathrm{C}$ and then $10^{\circ} \mathrm{C}$ per min to $150^{\circ} \mathrm{C}$.

Quantification had to be performed using standard addition, since the slope of the calibration curve in pure water was different from the one obtained by spiking the fermentation sample with standards. Standard addition was performed at three different levels using $50 \mu \mathrm{l}$ isobutanol standard solutions to certain volume of sample solutions. The corresponding addition were $7 \%$ to $100 \%, 40 \%$ to $150 \%$, and $57 \%$ to $300 \%$ extra isobutanol. The $\mathrm{R}^{2}$ values of the corresponding addition curves were in all cases larger than 0.96, and in most cases over 0.98 . The initial isobutanol concentration was extrapolated by the readings changed before and after adding the standard solutions. Quantification of 2methylbutanol and 3-methylbutanol was performed by using isobutanol as the internal standard. The response factor difference of 2-methylbutanol and 3-methylbutanol versus isobutanol were determined by calibration with mixtures of isobutanol, 2-methylbutanol and 3methylbutanol spiked into the media blank, at different concentrations similar to the ones observed in real samples.

\section{Acknowledgements}

The authors would like to acknowledge Peter Kötter for providing the applied yeast strain CEN.PK 2-1C. Uffe Hasbro Mortensen is acknowledged for his support and valuable comments. Furthermore, we would like to thank Jesper Mogensen and Jette Jepmond Mortensen for expert technical assistance. The authors gratefully acknowledge a contribution to the fellowship for XC from the SC Van Foundation, Denmark.

\section{Authors' contributions}

XC participated in design of the study, did all experimental work and participated in writing the manuscript. KFN designed the isobutanol analysis method and participated in writing the corresponding parts of the manuscript. IB participated in writing the manuscript. MCKB participated in design of the study and participated in writing the manuscript. KK participated in design of the study and in writing of the manuscript. All authors read and approved the final manuscript.

\section{Competing interests}

The authors declare that they have no competing interests.

Received: 18 November 2010 Accepted: 28 July 2011

Published: 28 July 2011

\section{References}

1. Connor MR, Liao JC: Microbial production of advanced transportation fuels in non-natural hosts. Curr Opin Biotechnol 2009, 20:307-315.

2. Cronk TC, Mattick LR, Steinkraus KH, Hackler LR: Production of higher alcohols during indonesian tape ketan fermentation. Appl Environ Microbiol 1979, 37:892-896.

3. Giudici P, Romano P, Zambonelli C: A biometric study of higher alcohol production in Saccharomyces cerevisiae. Can J Microbiol 1990, 36:61-64.

4. Atsumi S, Hanai T, Liao JC: Non-fermentative pathways for synthesis of branched-chain higher alcohols as biofuels. Nature 2008, 451:86-89.

5. Smith KM, Cho KM, Liao JC: Engineering Corynebacterium glutamicum for isobutanol production. Appl Microbiol Biotechnol 2010, 87:1045-1055.

6. Hohmann S: Osmotic adaptation in yeast-control of the yeast osmolyte system. In Molecular Mechanisms of Water Transport Across Biological 
Membranes. Volume 215. Edited by: Zeuthen T, Stein WD. Los Angeles, CA: Academic Press; 2002:149-188.

7. Knoshaug EP, Zhang M: Butanol tolerance in a selection of microorganisms. Appl Biochem Biotechnol 2009, 153:13-20.

8. Hazelwood LA, Daran JM, van Maris AJ, Pronk JT, Dickinson JR: The Ehrlich pathway for fusel alcohol production: a century of research on Saccharomyces cerevisiae metabolism. Appl Environ Microbiol 2008, 74:2259-2266.

9. Dickinson JR, Harrison SJ, Hewlins MJ: An investigation of the metabolism of valine to isobutyl alcohol in Saccharomyces cerevisiae. J Biol Chem 1998, 273:25751-25756.

10. Yoshimoto H, Fukushige T, Yonezawa T, Sone H: Genetic and physiological analysis of branched-chain alcohols and isoamyl acetate production in Saccharomyces cerevisiae. Appl Microbiol Biotechnol 2002, 59:501-508.

11. . Larry Cameron Anthony, Aston, PA (US), Lixuan Lisa Huang, Hockessin, DE (US), Rick W. Ye, Hockessin, DE (US): Production of isobutanol in yeast mitochondria. Pub. No.: US 20100129886A1. Washington, DC, USA: US Patent Office; 2010.

12. , Reid M. Renny Feldman, Highlands Ranch, CO (US), Uvini Gunavardena, Irvine, CA (US), Jun Urano, Aurora, CO (US), Peter Meinhold, Denver, CO (US), Aristos A. Aristidou, Highlands Ranch, CO (US), Catherine Asleson Dundon, Englewood, CO (US), Christopher Smith, Englewood, CO (US): Yeast organism producing isobutanol at high yield. Pub. No.: US 20090226991 A1. Washington, DC, USA: US Patent Office; 2009.

13. Berben G, Dumont J, Gilliquet V, Bolle PA, Hilger F: The YDp plasmids: a uniform set of vectors bearing versatile gene disruption cassettes for Saccharomyces cerevisiae. Yeast 1991, 7:475-477.

14. Ferreira ID, Rosario VE, Cravo PV: Real-time quantitative PCR with SYBR Green I detection for estimating copy numbers of nine drug resistance candidate genes in Plasmodium falciparum. Malar J 2006, 5:1.

15. Yi CX, Zhang J, Chan KM, Liu XK, Hong Y: Quantitative real-time PCR assay to detect transgene copy number in cotton (Gossypium hirsutum). Anal Biochem 2008, 375:150-152.

16. Kispal G, Steiner H, Court DA, Rolinski B, Lill R: Mitochondrial and cytosolic branched-chain amino acid transaminases from yeast, homologs of the myc oncogene-regulated Eca39 protein. J Biol Chem 1996, 271:24458-24464.

17. Eden A, Simchen G, Benvenisty N: Two yeast homologs of ECA39, a target for c-Myc regulation, code for cytosolic and mitochondrial branchedchain amino acid aminotransferases. J Biol Chem 1996, 271:20242-20245.

18. Lilly M, Bauer FF, Styger G, Lambrechts MG, Pretorius IS: The effect of increased branched-chain amino acid transaminase activity in yeast on the production of higher alcohols and on the flavour profiles of wine and distillates. FEMS Yeast Res 2006, 6:726-743.

19. Sentheshanuganathan $\mathrm{S}$ : The mechanism of the formation of higher alcohols from amino acids by Saccharomyces cerevisiae. Biochem J 1960, 74:568-576.

20. Dickinson JR: Pathways of leucine and valine catabolism in yeast. Methods Enzymol 2000, 324:80-92.

21. Cullin C, Baudin-Baillieu A, Guillemet E, Ozier-Kalogeropoulos O: Functional analysis of YCLO9C: evidence for a role as the regulatory subunit of acetolactate synthase. Yeast 1996, 12:1511-1518.

22. Pang SS, Duggleby RG: Expression, purification, characterization, and reconstitution of the large and small subunits of yeast acetohydroxyacid synthase. Biochemistry 1999, 38:5222-5231.

\section{Submit your next manuscript to BioMed Central and take full advantage of:}

- Convenient online submission

- Thorough peer review

- No space constraints or color figure charges

- Immediate publication on acceptance

- Inclusion in PubMed, CAS, Scopus and Google Scholar

- Research which is freely available for redistribution

Submit your manuscript at www.biomedcentral.com/submit 